\title{
Contexts and Opportunities of e-Health Technology in Medical Care
}

\author{
Sojib Bin Zaman ${ }^{* 1}$, Naznin Hossain², Shad Ahammed ${ }^{3}$, Zubair Ahmed ${ }^{4}$
}

Quick Access Code

\begin{abstract}
Keeping up with a sound health is a fundamental right for the human beings. It also acts as an indicator of the socio-economic development of a country. However, nowadays keeping sound health is challenging because of rapidly increasing non-communicable diseases. Concurrently, we are on the edge of very fast technological advancement which includes usage of cellular technology, high-speed internet and wireless communications. These technologies and their unique applications are creating lots of new dimensions in health care system which is known as e-Health. The medical call centers, emergency tollfree telephone services are being used in all over the world. The newly developed electronic health system can play a vital role in the remote regions of emerging and developing countries although sometimes it seems difficult due to the lack of communication infrastructure. E-Health can be a promising aspect for providing public health benefits if it integrates with the conventional medical system. More strategic approaches are necessary for the planning, development, and evaluation of e-Health. This article is written to depict the existing and future opportunities of e-Health in health support system.
\end{abstract}

Keywords: e-Health, Health-Care.

\section{Introduction}

Technology has come forth as a thrust to make life easier in our day to day life. Transformation of technology in the medical sector has emerged through different platforms i.e. e-Health, m-Health, and Telemedicine. E-Health technology can be used to disseminate health-related information or services among the health care providers, patients, and clinics. Across-the-board, e-Health is a segment of health informatics which includes $\mathrm{m}$-Health and telemedicine [1]. Due to widespread availability, the wireless connection equipped with a mobile phone has turned the process of communication faster for the patients who also increased the health care utilization. Mobile technology is enabled to provide the remote monitoring benefits for the patients who are restricted in mobility but needs continuous intervention from clinics. It can increase the probabilities to avoid emergency condition by detecting his/her vital signs and biosignals. Comprehensive studies are taking place in the field of healthcare to discover new devices and create applications suited for clinical practices. The ultimate goal of eHealth is to ensure a rationalize treatment for all group of patients and to improve patient safety and disease outcomes [2]. The aim of this write-up is to briefly discuss the present and future applications of e-Health technology in health care.

\section{Implications of e-Health on Medical Science}

Currently, the world is experiencing a significant rise of smartphone users, claiming the

\section{Article Details}

Date Received: 28/04/2017 Date Revised: 30/04/2017 Date Accepted: 01/05/2017 Date Published: 01/05/2017 DOI: $10.5281 /$ zenodo. 570870 Editor(s): Varshil Mehta

\section{Author Affiliation}

1. Faculty of Public Health, Khon Kaen University, Thailand.

2. Department of Pharmacology, Dhaka Medical College, Bangladesh.

3. Department of Control, Microsystem, and Microelectronics; University of Bremen, Germany.

4. Department of Biomedical Engineering, Khulna University of Engineering and Technology, Bangladesh.

\section{Corresponding Author}

Sojib Bin Zaman

Address: Khon Kaen University, Thailand.

Email l'd: sojibbz@gmail.com

Copyright: (c) 2017. The Author(s). This is an open access article under the CC BY license. (http://creativecommons.org/lice nses/by/4.0)

\section{Competing Interest and Funding: NIL}

Cite as: Zaman, S., Hossain, N., Ahammed, S., \& Ahmed, Z. (2017). Contexts and Opportunities of eHealth Technology in Medical Care. Journal Of Medical Research And Innovation, 1(2), AV1-AV4. doi:10.5281/zenodo.570870 
figure to be around 8.5 billion globally [3] . The mobile phone has become an indispensable part of our everyday life. Therefore, any health-related intervention through mobile application demands high chance of acceptability among the user. Global Positioning System (GPS), short message services (SMS) and video conferencing through WLAN/GPRS/3G network to locate a patient who needs immediate support are available. In contrast, the patient can determine his/her physical condition by understanding self-bio-signal and can take a decision of when to go for doctor's consultancy. Chronic diseases are the most common causes of death around the world [4]. The traditional system of episodic care in the clinic and hospital-based has found not to be enough to overcome chronic diseases [5]. For example, an integrated care installed within a device can offer the COPD patients to approach into a self-management; thus promoting the patient to accept prior treatment [6]. According to World Health Organization, increased adherence to medication can support the patients with chronic disease to live in a better way. Therefore, there are areas where the application of e-Health technology is feasible and needs to be implemented to increase patient compliance and treatment adherence. Telemedicine is the oldest form of eHealth which was introduced in the 1920s. After the remarkable success of health informatics in providing patient care, the rapid expansion of eHealth technology went forth during the 20th century [2]. As most of the e-Health technology is based on the application of electronic communication, it has found to be acted in remote regions [7]. Hence, e-Health can be used as a vital tool in responding the post-disaster emergency to counter human loss [8]. For example, telemedicine and telehealth have been successfully used recently in the aftermath of Hurricanes Katrina and Ike in USA [9]. International investment to build up e-Health technology for this country has abruptly increased as well. Countries like
England and USA have invested a significant amount of money to build up Information Technology (e-Health) to provide Health Service for its population [10].

\section{Application of mobile devices and apps in medical care}

Technologically equipped cellular interventions are widely accepted in healthcare to deliver quality services [11]. For example, $\mathrm{m}$-Health is providing different health interventions (preventive, promotive, and rehabilitative care) among all people [12]. $\mathrm{m}$-Health in the form of cellular communication is becoming popular among all group of people due to its handy, reliable and easy features [13]. Text messaging or short message service (SMS) have ensured broad coverage in developing countries due to its low price which facilitates the process of accessibility. It can also receive instant feedback from the target group and give them prompt feedback in case of an emergency [14]. Therefore, text messaging and phone calling offer a possible channel to render health behavior changing communications among the people [14]. For example, during the pregnancy period, advanced communication over the telephone can motivate the mothers to seek proper health care [15]. Phone call intervention can solve problems related to illiteracy or limited understanding of language barrier. In the case of inability of the patient's to answer the call, a voice message (recorded) service can also play the alternate role. M-health can also be introduced in Maternal and Child health care, HIV/AIDS, Malaria, Tuberculosis and many other diseases [9] ]. Health care professionals are using mobile devices and applications (figure 1) in the way of information management, time management, health record maintenance, consultation, clinical decision making, patient monitoring, medical education, and training to support the entire health system [16].

\begin{tabular}{|c|c|c|}
\hline $\begin{array}{l}\text { Information } \\
\text { Management } \\
\text { Write notes } \\
\text { Dictate notes } \\
\text { Record audio } \\
\text { Take photographs } \\
\text { Use e-book reader } \\
\text { Access cloud service } \\
\text { Time Management } \\
\text { Schedule } \\
\text { appointments } \\
\text { Schedule meetings } \\
\text { Record call schedule } \\
\text { Patient Monitoring } \\
\text { Monitor patient } \\
\text { health } \\
\text { Monitor patient } \\
\text { location } \\
\text { Monitor patient } \\
\text { rehabilitation } \\
\text { Collect clinical data }\end{array}$ & $\begin{array}{l}\text { Consultations } \\
\text { Voice calling } \\
\text { Video calling } \\
\text { Texting \& E-mail } \\
\text { Video conferencing } \\
\text { Social networking } \\
\text { Information } \\
\text { Gathering } \\
\text { Medical textbooks } \\
\text { Medical journals } \\
\text { Medical literature } \\
\text { Literature search } \\
\text { Drug reference guides } \\
\text { Medical News } \\
\text { Health Record } \\
\text { Maintenance } \\
\text { Access EMRs } \\
\text { Electronic prescribing } \\
\text { Coding and billing }\end{array}$ & $\begin{array}{l}\text { Medical Education } \\
\text { and Training } \\
\text { Continuing medical } \\
\text { education } \\
\text { Board exam } \\
\text { preparation } \\
\text { Case studies } \\
\text { E-learning } \\
\text { Surgical simulation } \\
\text { Skill assessment tests } \\
\text { Clinical Decision- } \\
\text { Making } \\
\text { Clinical decision } \\
\text { support systems } \\
\text { Disease diagnosis } \\
\text { Medical calculators } \\
\text { Laboratory test } \\
\text { interpretation }\end{array}$ \\
\hline
\end{tabular}

Figure 1. Mobile devices and their applications for health workers (Source: Ventola. 2014). 
The most frequently reported types of $\mathrm{m}$-Health initiatives are health call centers, mobile help lines, and toll-free telephone services. Telehealth offers several benefits to the patients. Utilization of telehealth can increase the access to health services, enhance provision of health education by providing cost-effective intervention [18]. Another study showed that video conferencing technology might be a cheaper and less time-consuming solution compared to traditional regular health care visits [19]. Integrating telehealth with the healthcare institution's electronic database can reduce resource usage and also can improve treatment compliance for the people who are homebound and disable [20]. Therefore, the patient can found themselves safe and maintain a secured life by utilizing different devices which enable them to be prepared in emergency condition as well.

\section{Implementation of e-Health technology in Major scale}

Electronic and internet-based data transmission, data storage, data safety and confidentiality issues will become the major concern in upcoming years. Moreover, applications of all technologies have limitations, and they are not designed to provide their benefits under every circumstance. For example, most of the health monitoring software runs on the user's smartphone and analyses the data received from the sensors. For the younger generation, using such software can be a natural choice. However, it can be complicated and a challenged phenomenon for the more elderly population. Universal health care is essential, and it needs to be implemented in developing countries [21].

Implementation of e-Health has the potential to cover the health need of rural people. Although providing the real-time data can be a challenge for those who are in need of monitoring devices. Maintenance and expert handling to operate these devices can be somehow cumbersome as well.

e-Health is an umbrella term that combines healthcare and technology to support people in a more efficient way, and it can also reduce health-related costs. Some developed countries who have been implementing health-related interventions, they always consider eHealth to be of top priority. However, the fruitful application of eHealth depends upon the multidisciplinary approaches [2].

Teams must have the necessary expertise for the understanding of specific eHealth project (figure 2). The team includes scientists, physicians, nurses, pharmacists, information technology expert, policy makers as well as the patients [22]. However, there is a great promise that implementing eHealth can improve the total health care system in both developed and developing countries. eHealth is called to be an end-to-end process and is adapted to use under all circumference.

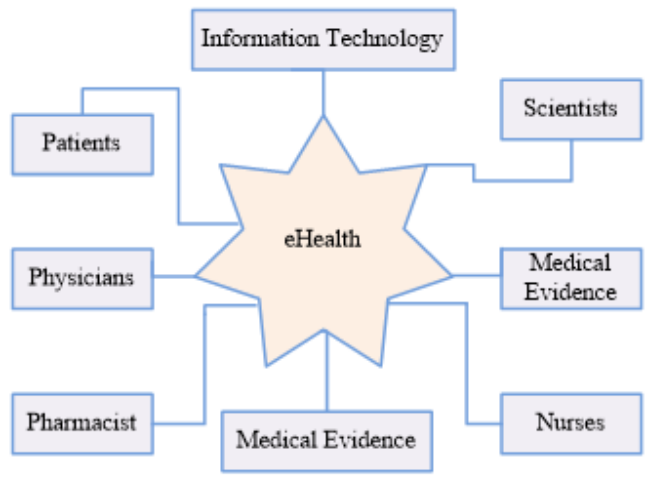

Figure 2: Future multidimensional approach of e-Health (Source: Van Rooij. 2016)

Therefore, we can take the benefit of e-Health by using its' different platform. Under all circumstances from birth registration to death registries, screening to follow-up, emergency intervention to homecare e-Health technology can be used as a vital tool [3]. Clinical Decision Support Systems refers to the computer architecture of specific software apps which can provide Clinical Decision Support (CDS) to the patient. In future, CDS will assist healthcare providers to take accurate decisions by providing rapid and efficient access to relevant medical data [2] and will be able to improve the health infrastructure. Thus, it might help a lot to reduce the treatment cost and give better services to the patients. However, there are many obstacles and challenges for the development, implementation, adoption and acceptance of CDSS which can be the future opportunity to research.

\section{Conclusion}

e-Health can be considered to be a promising vehicle for health care provision. More strategic approaches are necessary for the planning, development, and implementation of $\mathrm{m}$-Health. International and national health organizations should focus more on the improvement of e-health technology to make it adapted for the benefits of patients. However, m-Health should not be considered as an ultimate remedy to increase the coverage of health care delivery. It should go side by side along with regular clinical visit and follow-up practices. Finally, new and uprising eHealth technologies have huge potential to bridge the gaps between patient and healthcare support providers. Incorporating technology into the medical care can ensure patient-centered health care system. 


\section{References}

1. Gustafson, D., Wyatt, J. (2004). Evaluation of ehealth systems and services. Bmj 328(7449), 1150.

2. Van, R., Marsh, S. (2016). eHealth: past and future perspectives. Personalized Medicine 13(1), 57-70. https://doi.org/10.2217/pme.15.40

3. Kakria, P., Tripathi, N., Kitipawang, P. (2015). A real-time health monitoring system for remote cardiac patients using smartphone and wearable sensors. International journal of telemedicine and applications 2015, 8. https://doi.org/10.1155/2015/373474

4. Viswanathan, M., Golin, C., Jones, C., Ashok, M., Blalock, S., Wines, R., et, a. (2012). Interventions to improve adherence to self-administered medications for chronic diseases in the United States: a systematic review. Annals of internal medicine 157(11), 785-95. https://doi.org/10.7326/0003-4819-157-11-20121204000538

5. Nilsen, W., Kumar, S., Shar, A., Varoquiers, C., Wiley, T., Riley, W., et, a. (5). Advancing the science of mHealth. Journal of health communication 2012;17(sup1): https://doi.org/10.1080/10810730.2012.677394

6. Koff, P., Jones, R., Cashman, J., Voelkel, N., Vandivier, R. (2009). Proactive integrated care improves quality of life in patients with COPD. European Respiratory Journal 33(5),

1031-8. https://doi.org/10.1183/09031936.00063108

7. Della, M. (2001). What is e-Health (2): The death of telemedicine? Journal of Medical Internet Research. 3(2), e22. https://doi.org/10.2196/jmir.3.2.e22

8. Doarn, C., Merrell, R. (2014). Telemedicine and e-health in disaster response. Mary Ann Liebert, Inc 140 Huguenot Street, 3rd Floor New Rochelle, NY 10801 USA; https://doi.org/10.1089/tmj.2014.9983

9. Kim, T., Arrieta, M., Eastburn, S., Icenogle, M., Slagle, M., Nuriddin, A., et, a. (2013). Post-disaster Gulf Coast recovery using telehealth. TELEMEDICINE and e-HEALTH 19(3), 200-10. https://doi.org/10.1089/tmj.2012.0100

10. Catwell, L., Sheikh, A. (2009). Evaluating eHealth interventions: the need for continuous systemic evaluation. PLoS Med 6(8), e1000126. https://doi.org/10.1371/journal.pmed.1000126

11. Free, C., Phillips, G., Galli, L., Watson, L., Felix, L., Edwards, P., et, a. (2013). The effectiveness of mobile-health technology-based health behaviour change or disease management interventions for health care consumers: a systematic review. PLoS med 10(1), e1001362. https://doi.org/10.1371/journal.pmed.1001362
12. Kay, M., Santos, J., Takane, M. (2011). mHealth: New horizons for health through mobile technologies. World Health Organization 64(7), 66-71.

13. Lagan, B., Sinclair, M., George, K. (2010). Internet use in pregnancy informs women's decision making: a web-based survey. Birth 37(2), 106-15. https://doi.org/10.1111/j.1523-536X.2010.00390.x

14. Fjeldsoe, B., Miller, Y., Marshall, A. (2012). Text messaging interventions for chronic disease management and health promotion. eHealth Applications: Promising Strategies for Health Behavior Change 167-86.

15. Zaman, S., Hossain, N., Yasir, A., Sharmin, S. (2017). Management of Newborn Infection: Knowledge and attitude among health care providers of selected subdistrict hospitals in Bangladesh. International Journal of Perceptions in Public Health 1(2), 127-32.

16. Ventola, C. (2014). Mobile devices and apps for health care professionals: uses and benefits. PT 39(5), 356-64.

17. Rahman, A., Iqbal, A., Hoque, D., Moinuddin, M., Zaman, S., Rahman, Q., et, a. (2017). Managing Neonatal and Early Childhood Syndromic Sepsis in Sub-District Hospitals in Resource Poor Settings: Improvement in Quality of Care through Introduction of a Package of Interventions in Rural Bangladesh. PloS one 12(1), e0170267.

https://doi.org/10.1371/journal.pone.0170267

18. Jennett, P., Hall, L., Hailey, D., Ohinmaa, A., Anderson, C., Thomas, R., et, a. (2003). The socio-economic impact of telehealth: a systematic review. Journal of telemedicine and telecare 9(6), 311-20. https://doi.org/10.1258/135763303771005207

19. Noel, H., Vogel, D., Erdos, J., Cornwall, D., Levin, F. (2004). Home telehealth reduces healthcare costs. Telemedicine Journal \& e-Health 10(2), 170-83. https://doi.org/10.1089/tmj.2004.10.170

20. Finkelstein, S., Speedie, S., Potthoff, S. (2006). Home telehealth improves clinical outcomes at lower cost for home healthcare. Telemedicine Journal \& e-Health 12(2), 128-36. https://doi.org/10.1089/tmj.2006.12.128

21. Zaman, S., Hossain, N. (2017). Universal Health Coverage: A burning need for developing countries. Journal of Medical Research and Innovation 1(1), 18-20. https://doi.org/10.5281/zenodo.546770

22. Zaman, S. (2017). Importance of Learning the Public Health Leadership. Public Health of Indonesia 3(1), 1-3. 